\title{
Mechanism of one-electron oxidation of metformin in aqueous solution $\dagger$
}

\author{
P. Trouillas, ${ }^{\star a b c}$ C. Marchetti, ${ }^{d}$ D. Bonnefont-Rousselot, ${ }^{\text {ef }}$ R. Lazzaroni, ${ }^{b}$ D. Jore, ${ }^{d}$ \\ M. Gardès-Albert ${ }^{d}$ and F. Collin*dgh
}

Hydroxyl free radical-induced oxidation of metformin was studied in aqueous solution as a function of the

Received 8th February 2013, Accepted 19th April 2013

DOI: $10.1039 / \mathrm{c} 3 \operatorname{cp} 50602 a$

www.rsc.org/pccp $\mathrm{pH}$. Hydroxyl free radicals were generated by gamma radiolysis of water and the oxidation end-products were quantified by high-performance liquid chromatography coupled to mass spectrometry (HPLC/MS), as a function of the radiation dose. This work is a joint experimental and theoretical (DFT) approach that has paved the way towards a comprehensive rationalization of the one-electron mechanisms of MTF oxidation, as a function of the $\mathrm{pH}$.

\section{Introduction}

Metformin (MTF), or N,N-dimethylbiguanide (Fig. 1), is the most widely prescribed drug for the treatment of type 2 diabetes. It mainly acts by activation of AMP-activated protein kinase (AMPK), a master regulator of cell metabolism. ${ }^{1}$ This AMPK activation may also play a role in preventing the formation and progression of cancer, and MTF has recently demonstrated its activity in reducing tobacco carcinogen-induced lung tumour genesis in mice. ${ }^{2}$ Besides these properties, MTF has been shown to exhibit antioxidant properties, either directly or indirectly. ${ }^{3-9}$ However, the mechanism of action by which MTF displays its

a INSERM UMR-S850, Faculté de Pharmacie, Université de Limoges,

2 rue du Docteur Marcland, 87025 Limoges Cedex, France.

E-mail: patrick.trouillas@unilim.fr

${ }^{b}$ Laboratoire de Chimie des Matériaux Nouveaux,

Université de Mons Place du Parc 20, B-7000 Mons, Belgium

${ }^{c}$ Regional Centre of Advanced Technologies and Materials, Department of Physical Chemistry, Faculty of Science, Palacký University Olomouc, tr. 17 listopadu,

77146 Olomouc, Czech Republic

${ }^{d}$ UFR Biomédicale des Saints-Pères, Université Paris Descartes,

45 rue des Saints Pères, 75006 Paris, France

${ }^{e}$ EA 4466, Département de Biologie Expérimentale, Métabolique et Clinique, Faculté des Sciences Pharmaceutiques et Biologiques, Université Paris Descartes, 4 avenue de l'Observatoire, 75006 Paris, France

${ }^{f}$ Service de Biochimie Métabolique, Hôpitaux Universitaires Pitié-Salpêtrière Charles Foix (AP-HP), 47-83 boulevard de l'Hôpital, 75013 Paris, France

${ }^{g}$ Université de Toulouse, UPS, UMR 152 Pharma-Dev, Université Toulouse 3, F-31062 Toulouse cedex 09, France

${ }^{h}$ Institut de Recherche pour le Développement (IRD), UMR 152 Pharma-Dev, F-31062 Toulouse cedex 09, France. E-mail: fabrice.collin@univ-tlse3.fr $\dagger$ Electronic supplementary information (ESI) available: Detailed information on MTF consumption and oxidation product generation as a function of the radiation dose, at pH 2.8, 7.15 and 11.6 (Fig. S1-S3). See DOI: 10.1039/c3cp50602a
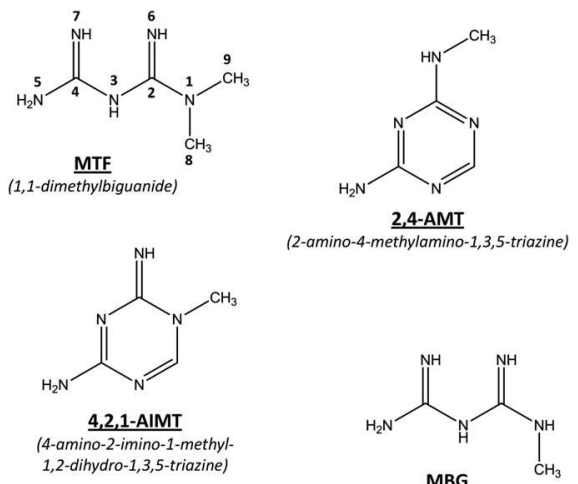

(2-amino-4-methylamino-1,3,5-triazine)
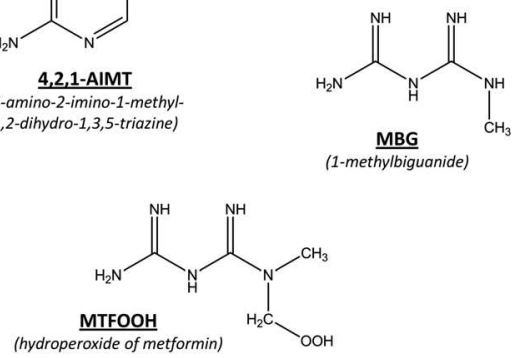

Fig. 1 Chemical structures of metformin (MTF) and its radio-induced oxidation end-products: hydroperoxide of metformin (MTFOOH), methylbiguanide (MBG), 2-amino-4-methylamino-1,3,5-triazine (2,4-AMT), and 4-amino-2-imino-1-methyl-1, 2-dihydro-1,3,5-triazine (4,2,1-AIMT).

direct antioxidant effect, i.e., scavenging of oxygen-derived radical species, has not been totally unravelled. We previously investigated the capacity of one-electron oxidation of MTF by $\mathrm{HO}^{\bullet}$ free radicals, generated by gamma radiolysis; oxidation end-products were clearly identified. ${ }^{10}$ At low radiation dose, four primary products, resulting from the direct attack of $\mathrm{HO}^{\bullet}$ radicals on MTF, were identified i.e., (i) hydroperoxide of MTF (MTFOOH), (ii) a covalent dimer of MTF, only observed in deaerated medium, (iii) methylbiguanide (MBG) and (iv) 2-amino-4-methylamino-1,3,5-triazine (2,4-AMT), exhibiting an isomeric form 4-amino-2-imino-1-methyl-1, 
2-dihydro-1,3,5-triazine (4,2,1-AIMT) (Fig. 1). Under similar experimental conditions, the superoxide radicals appeared to be poor initiators of MTF oxidation, thereby suggesting that MTF is not a powerful antioxidant, being mainly oxidized by $\mathrm{HO}^{\bullet}$ radicals. ${ }^{11}$ Even for these very reactive free radicals, the reaction with MTF exhibited a relatively low rate constant (\#107 $\mathrm{L} \mathrm{mol}^{-1} \mathrm{~s}^{-1}$ ), showing a nondiffusion-controlled process $\left(k\right.$-values $\left.=10^{9}-10^{10} \mathrm{~mol}^{-1} \mathrm{~L} \mathrm{~s}^{-1}\right){ }^{11}$

In order to fully rationalize the $\mathrm{HO}^{\bullet} / \mathrm{O}_{2}{ }^{\bullet-}$-induced oxidation mechanism of MTF, the present manuscript describes the radiation dose effect (from 5 to $50 \mathrm{~Gy}$ ). The radiolytic yields related to the concomitant MTF consumption and formation of oxidation products are determined and allow dealing with the balance between MTF disappearance and the sum of product formation.

Importantly in this work, the radiolytic process is experimentally demonstrated not only at neutral $\mathrm{pH}$ (7.15), but also at pH 2.8 and 11.6 corresponding to the $\mathrm{p} K_{\mathrm{a}}$-values of $\mathrm{di}-/ \mathrm{mono}-$ protonated MTF and mono-/non-protonated MTF acid-base couples, respectively. Our results underline the difference in reactivity of MTF under acidic conditions ( $\mathrm{pH} 2.8$ ) on one hand, and neutral or basic conditions ( $\mathrm{pH} 7.15$ or 11.6) on the other hand. These results are supported by density functional theory (DFT) calculations, allowing the estimation of the antioxidant capacity of MTF and the Gibbs energies of formation for the different oxidation products.

\section{Methods}

\section{Chemicals and preparation of aqueous solutions}

MTF hydrochloride and 2,4-diamino-6-methyl-1,3,5-triazine (DMT) were purchased from Sigma Aldrich (St. Louis, MO, USA). Buformin (BUF) was purchased from LGC Calbiochem and methylbiguanide (MBG) from Labotest (Niederschöna, Germany). Ultra-pure water (Maxima Ultra Pure Water, ELGA, resistivity $18 \mathrm{M} \Omega$ ) was used throughout the study. Stock solutions of $200 \mu \mathrm{mol} \mathrm{L}{ }^{-1} \mathrm{MTF}$ were prepared and $\mathrm{pH}$ was adjusted by adding $\mathrm{HClO}_{4}$ (Sigma Aldrich (St. Louis, MO, USA)) or $\mathrm{NaOH}$ (Merck, Germany) to reach the required pH 2.8, 7.15 or 11.6. The $\mathrm{pH}$ was measured using a PHM210 $\mathrm{pH}$ meter (Radiometer analytical, France). Two of these pH-values, i.e., 2.8 and 11.6, corresponded to the $\mathrm{p} K_{\mathrm{a}} \mathrm{s}$ of $\mathrm{MTF} .{ }^{12}$ The MTF concentration was chosen because $200 \mu \mathrm{mol} \mathrm{L}{ }^{-1}$ was at the plateau of the dilution curve, ${ }^{11}$ which implies that all $\mathrm{HO}^{\bullet}$ radicals reacted with MTF, without any competition with $\mathrm{H}_{2} \mathrm{O}_{2}$ produced during gamma radiolysis. The same concentration was also used for the previous HPLC/MS identification of oxidation products of MTF. ${ }^{10}$

\section{Gamma irradiation}

Gamma irradiation was carried out using an IBL 637 irradiator (CIS Bio International, Gif-sur-Yvette, France) with a $\gamma$-ray source of ${ }^{137} \mathrm{Cs}$ whose activity was $\approx 222 \mathrm{TBq}(6000 \mathrm{Ci})$. The dosimetry was performed using the Fricke method, ${ }^{13}$ namely radio-oxidation of $10^{-3} \mathrm{~mol} \mathrm{~L}^{-1}$ ferrous sulphate solution in $0.4 \mathrm{~mol} \mathrm{~L}^{-1}$ sulphuric acid (under aerated atmosphere) taking $\lambda_{\max }\left(\mathrm{Fe}^{3+}\right)=304 \mathrm{~nm}$, $\varepsilon_{(304 \mathrm{~nm})}=2204 \mathrm{~L} \mathrm{~mol}^{-1} \mathrm{~cm}^{-1}$ at $25{ }^{\circ} \mathrm{C}$, and a radiolytic yield of $G\left(\mathrm{Fe}^{3+}\right)=16.2 \times 10^{-7} \mathrm{~mol} \mathrm{~J}{ }^{-1}$. The dose-rate was $7.5 \mathrm{~Gy} \mathrm{~min}^{-1}$.
Different radiation doses, ranging from 5 to $50 \mathrm{~Gy}$, were delivered to $5 \mathrm{~mL}$ aqueous solution of MTF, depending on the time the sample was exposed to the $\gamma$-ray source: the longer the exposure, the higher the radiation dose. For each experimental set, $5 \mathrm{~mL}$ of non-irradiated solution was taken as a control.

Gamma radiolysis of water generates the $\mathrm{e}_{\mathrm{aq}}{ }^{-}, \mathrm{HO}^{\bullet}$ and $\mathrm{H}^{\bullet}$ free radical species, and the $\mathrm{H}_{2}$ and $\mathrm{H}_{2} \mathrm{O}_{2}$ molecular species. At $\mathrm{pH} 7$ in the presence of dioxygen (aerated solution), two radical species were quantitatively formed: $\mathrm{HO}^{\bullet}$ and $\mathrm{O}_{2}{ }^{\bullet-}$ (resulting from the scavenging of $\mathrm{e}_{\mathrm{aq}}{ }^{-}$and $\mathrm{H}^{\bullet}$ by $\mathrm{O}_{2}$ ), with the respective radiolytic yields ( $G$-value) of $2.8 \times 10^{-7}$ and $3.4 \times 10^{-7} \mathrm{~mol} \mathrm{~J}^{-1} \cdot{ }^{14}$ At pH 7.15 and 11.6, the acidic form $\mathrm{HO}_{2}{ }^{\bullet}\left(\mathrm{p} K_{\mathrm{a}}\left(\mathrm{HO}_{2}{ }^{\bullet} \mathrm{O}_{2}{ }^{\bullet-}\right)=4.8\right)^{15}$ is negligible compared to $\mathrm{O}_{2}{ }^{--}$species. By contrast, at pH 2.8, $\mathrm{O}_{2}{ }^{\bullet-}$ is negligible compared to $\mathrm{HO}_{2} \cdot$.

\section{Analyses}

MTF and its oxidation products were separated and quantified by high-pressure liquid chromatography coupled to ion trap mass spectrometry (HPLC/MS, LCQ Advantage, ThermoScientific, Les Ulis, France), equipped with an electrospray ionization source (ESI). The capillary temperature was held at $250{ }^{\circ} \mathrm{C}$ and the relative sheath and auxiliary gas flow-rates were set at 20 and 5 respectively (sheath gas, 0-100 units, corresponds to 0-1.5 $\mathrm{L} \mathrm{min}^{-1}$; auxiliary gas, 0-60 units, corresponds to $0-18 \mathrm{~L} \mathrm{~min}^{-1}$, according to the manufacturer's specifications). All experiments were performed in the positive-ion mode. Calibration solutions containing MTF, DMT and MBG at final concentrations ranging from 1 to $10 \mu \mathrm{mol} \mathrm{L}^{-1}$ were prepared and $\mathrm{pH}$ was adjusted to $2.8,7.15$ or 11.6. BUF $(500 \mu \mathrm{L})$, used as an internal standard, was added to every sample and standard solutions (volume $5 \mathrm{~mL}$ ) to reach a final BUF concentration of $10 \mu \mathrm{mol} \mathrm{L} \mathrm{L}^{-1}$. A volume of $20 \mu \mathrm{L}$ of sample was injected on a reversed-phase column, $250 \times 2.1 \mathrm{~mm}$ Atlantis dC18 $5 \mu \mathrm{m}$ (Waters, St Quentin en Yvelines, France). Elution was performed at room temperature in isocratic mode with 50/50 (v/v) acetonitrile/ammonium acetate $(10 \mathrm{mM}, \mathrm{pH}$ ), at a flow-rate of

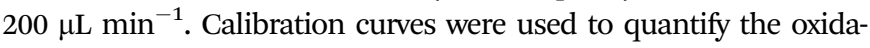
tion products of MTF.

Remaining non-oxidized MTF was quantified by HPLC coupled to a dual wavelength UV-visible spectrophotometer (Waters 2487, Guyancourt, France), running at $232 \mathrm{~nm}$ (wavelength of maximal absorption for MTF). An external calibration curve was built with solutions of MTF from 185 to $200 \mu \mathrm{mol} \mathrm{L}{ }^{-1}$, for which $\mathrm{pH}$ was adjusted to $2.8,7.15$ or 11.6. A volume of $10 \mu \mathrm{L}$ of solution was injected on the same column as used for HPLC/MS quantifications. Results were expressed as mean \pm SD of at least 5 independent experiments.

Trace chromatograms for the detected ions related to MTF $(\mathrm{m} / \mathrm{z} 130)$ and its radical-induced oxidation products $\mathrm{MTFOOH}$ $(\mathrm{m} / \mathrm{z}$ 162), 2,4-AMT and 4,2,1-AIMT $(\mathrm{m} / \mathrm{z} 126)$, MBG $(\mathrm{m} / \mathrm{z} 116)$ are shown as ESI, $\dagger$ together with that of BUF used as an internal standard $(\mathrm{m} / \mathrm{z}$ 158).

\section{Methods for calculation}

$\mathrm{R}-\mathrm{H}$ bond dissociation enthalpies (BDEs) were calculated as the difference, in total enthalpy, at $298 \mathrm{~K}$, between the primary 
radical $\left([\mathrm{MTF}-\mathrm{H}]^{\bullet}\right.$ ) formed after $\mathrm{H}$-atom abstraction (HAT) and metformin (MTF), according to:

$$
\mathrm{MTF} \rightarrow[\mathrm{MTF}-\mathrm{H}]^{\bullet}+\mathrm{H}^{\bullet}
$$

DFT appeared to be particularly adapted to evaluate antioxidant properties, mainly by the calculation of bond dissociation enthalpies of $\mathrm{H}$-atom donor groups, hybrid functionals being particularly adapted e.g., B3LYP. ${ }^{16,17}$ The use of polarizable functions in the basis sets, especially for the hydrogen atom, has been demonstrated to be of importance to provide accuracy in the estimation of BDE. The use of diffuse function could also improve the description of these systems for which $\pi$-conjugation is crucial. The calculation was thus performed at the B3LYP/6-31+G(d,p) level.

All $[\mathrm{MTF}-\mathrm{H}]^{\bullet}$ radicals, obtained after HAT from MTF, were evaluated by using an unrestricted scheme (U) in order to properly account for spin polarization. Geometry optimization for each radical was performed starting from the optimized structure of the parent molecule (MTF), after the $\mathrm{H}$ atom was removed from the different positions. The solvent effect was taken into account implicitly using a polarizable continuum model (PCM) approach, in which the solute is embedded in a shape-adapted cavity surrounded by a polarizable dielectric representing the solvent. The dielectric medium is described by its dielectric constant ( $\varepsilon=78.39$ for water).

To study thermodynamics and kinetics of reactions the enthalpies $(H)$ and Gibbs energies $(G)$ were obtained at $298 \mathrm{~K}$. All transition states (TS) were confirmed by the presence of one imaginary frequency for the mode of vibration corresponding to the reaction coordinate of the reaction under study (e.g., bond formation and bond breaking). The transition states were also confirmed using the IRC (Integrated Reaction Coordinates) procedure, confirming the formation of the expected products.

All results reported in this work are based on (U)B3LYP/ 6-31+G(d,p) calculations of enthalpy differences at $298 \mathrm{~K}$, with or without influence of the PCM solvent. All calculations were carried out using Gaussian03 software. ${ }^{18}$

\section{Results and discussion}

\section{Kinetics of MTF radio-induced oxidation}

As previously shown, the radical-induced oxidation of MTF was found to lead to hydroperoxide of MTF (MTFOOH), methylbiguanide (MBG) and 2-amino-4-methylamino-1,3,5-triazine (2,4-AMT), which is able to further evolve into the isomeric form 4 -amino2-imino-1-methyl-1,2-dihydro-1,3,5-triazine (4,2,1-AIMT). ${ }^{10}$ These products were detected in the present study, at pH 2.8, 7.15 and 11.6 (Fig. 2), when MTF in aqueous solution was irradiated at $50 \mathrm{~Gy}$. Among the two cyclic oxidation products, the formation of 2,4-AMT appears as being $\mathrm{pH}$-dependent since the latter is only detected at $\mathrm{pH}$ 11.6. At this $\mathrm{pH}$, the consumption of MTF as a function of the radiation dose (ESI, $\uparrow$ Fig. S1) shows a quasi-linear decrease of MTF concentration that provides a $G(-\mathrm{MTF})$ radiolytic yield equal to $(2.70 \pm 0.60) \times 10^{-7} \mathrm{~mol} \mathrm{~J}^{-1}$ (reported in Table 1 ), determined as the slope of the initial tangent of the curve. Such a value was almost equal to the radiolytic yield known for the
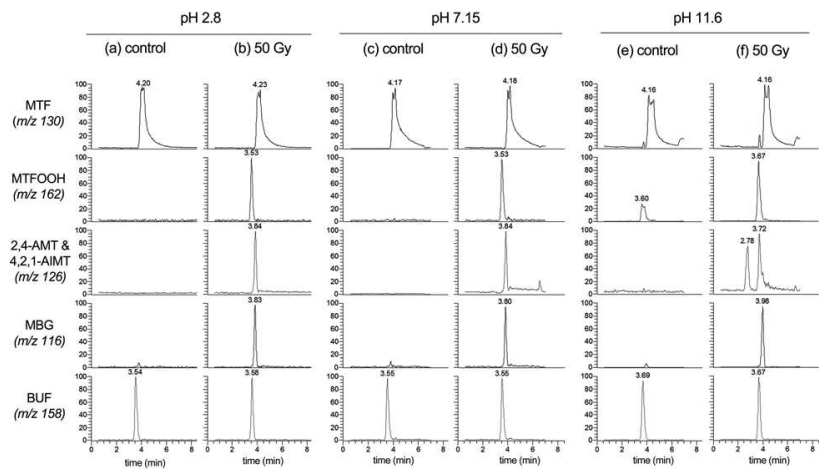

Fig. 2 Detection of MTF and its radio-induced oxidation end-products at $\mathrm{pH} 2.8$, 7.15 and 11.6. Trace chromatograms for each detected ion, for aqueous solutions of MTF $\left(200 \mu \mathrm{mol} \mathrm{L}{ }^{-1}\right)$, at $\mathrm{pH} \mathrm{2.8,} 7.15$ and 11.6, non-irradiated $(\mathrm{a}, \mathrm{c}, \mathrm{e})$ or irradiated at $50 \mathrm{~Gy}(\mathrm{~b}, \mathrm{~d}, \mathrm{f})$. Abscissa, retention time; ordinate, relative intensity. $\mathrm{MTF}=$ metformin; $\mathrm{MTFOOH}=$ hydroperoxide of metformin; 2,4-AMT = 2-amino4-methylamino-1,3,5-triazine; 4,2,1-AIMT = 4-amino-2-imino-1-methyl-1,2-dihydro1,3,5-triazine; MBG = methylbiguanide; BUF = buformin (internal standard).

$\mathrm{HO}^{\bullet}$ production (i.e., $2.8 \times 10^{-7} \mathrm{~mol} \mathrm{~J}^{-1}$ ). Simultaneously, four oxidation products namely $\mathrm{MTFOOH}, \mathrm{MBG}, 2,4-\mathrm{AMT}$ and its isomer 4,2,1-AIMT were produced from MTF (ESI, $\uparrow$ Fig. S1). It is noteworthy that a low MTFOOH concentration was present in MTF solutions before any irradiation, reflecting a partial autooxidation. However, the MTFOOH concentration linearly increased with radiation dose, providing a $G(\mathrm{MTFOOH})$ yield of $(0.31 \pm 0.04) \times 10^{-7} \mathrm{~mol} \mathrm{~J}^{-1}$.

A negligible MBG concentration pre-existed in non-irradiated MTF solutions, which dramatically increased with radiation dose therefore providing a $G(\mathrm{MBG})$ yield of $(1.40 \pm 0.20) \times 10^{-7} \mathrm{~mol} \mathrm{~J}^{-1}$. The other two oxidation products i.e., both isomers 2,4-AMT and 4,2,1-AIMT, were absent in non-irradiated MTF solutions and were produced with relatively low yields under irradiation $((0.36 \pm 0.08) \times$ $10^{-7} \mathrm{~mol} \mathrm{~J}^{-1}$ and $(0.41 \pm 0.04) \times 10^{-7} \mathrm{~mol} \mathrm{~J}^{-1}$, respectively $)$.

A comprehensive status of the $G$-values of MTF consumption and oxidation product formation at $\mathrm{pH} 11.6$ is shown in Table 1 . The sum of $G$-values of the four observed oxidation products almost perfectly matched the $G(-\mathrm{MTF})$ value

Table 1 Radiolytic yields G $\left(10^{-7} \mathrm{~mol} \mathrm{~J}^{-1}\right.$, mean (SD)) of MTF disappearance and radiolytic yields of formation for the corresponding oxidation products (along with their sum, $\sum P_{\text {ox }}$ ), for solutions of MTF $200 \mu \mathrm{mol} \mathrm{L} \mathrm{L}^{-1}$ at $\mathrm{pH} 2.8,7.15$ and 11.6 irradiated at doses ranging from 5 to $50 \mathrm{~Gy}\left(I=7.5 \mathrm{~Gy} \mathrm{~min}^{-1}\right)$. Radiolytic yields are obtained by the slope of the initial tangent of the curves reported in Fig. S1-S3 (ESI). The relative amount (\%) of each product is given by the ratio between its production yield and the sum of G-values for all products. MTF = metformin; $\mathrm{MTFOOH}=$ hydroperoxide of metformin; 2,4-AMT = 2-amino4-methylamino-1,3,5-triazine; 4,2,1-AIMT = 4-amino-2-imino-1-methyl-1,2-dihydro1,3,5-triazine; $\mathrm{MBG}=$ methylbiguanide

\begin{tabular}{|c|c|c|c|c|c|c|}
\hline & \multicolumn{2}{|l|}{ pH 2.8} & \multicolumn{2}{|l|}{ pH 7.15} & \multicolumn{2}{|l|}{ pH 11.6} \\
\hline & $G$ & $\%$ & $G$ & $\%$ & $G$ & $\%$ \\
\hline MTF & $1.80(0.30)$ & - & $3.10(0.40)$ & - & $2.70(0.60)$ & - \\
\hline MTFOOH & $0.19(0.02)$ & 11 & $0.12(0.01)$ & 4 & $0.31(0.04)$ & 12 \\
\hline 2,4-AMT & - & - & $0.58(0.09)$ & 18 & $0.36(0.08)$ & 15 \\
\hline 4,2,1-AIMT & $0.83(0.05)$ & 51 & $0.90(0.09)$ & 27 & $0.41(0.04)$ & 17 \\
\hline MBG & $0.62(0.04)$ & 38 & $1.70(0.20)$ & 51 & $1.40(0.20)$ & 56 \\
\hline$\sum P_{\mathrm{ox}}$ & 1.64 & 100 & 3.30 & 100 & 2.48 & 100 \\
\hline
\end{tabular}


$\left(2.48 \times 10^{-7}\right.$ vs. $2.70 \times 10^{-7} \mathrm{~mol} \mathrm{~J}{ }^{-1}$, respectively). The main oxidation product formed at pH 11.6 was MBG (56\%), whereas MTFOOH, 2,4-AMT and 4,2,1-AIMT represented only 12, 15 and $17 \%$, respectively.

At $\mathrm{pH}$ 7.15, similar conclusions could be drawn (ESI, $\dagger$ Fig. S2), except that none of the oxidation products pre-existed before irradiation, showing a better stability of MTF aqueous solutions under neutral conditions with respect to the basic environment. The yield-value of MTF consumption was $(3.10 \pm 0.40) \times 10^{-7} \mathrm{~mol} \mathrm{~J}^{-1}$ (Table 1$)$, similar to that obtained at $\mathrm{pH}$ 11.6. The sum of the $G$-values for the oxidation products was $3.30 \times 10^{-7} \mathrm{~mol} \mathrm{~J}^{-1}$, showing a total recovery. As observed at $\mathrm{pH}$ 11.6, MBG was the main oxidation product $(51 \%)$, whereas MTFOOH, 2,4-AMT and 4,2,1-AIMT only accounted for 4,18 and $27 \%$, respectively.

At pH 2.8 (ESI, $†$ Fig. S3), MTF was consumed with a $G$-value lower than those at the other two $\mathrm{pH}$ values, since it was $(1.80 \pm$ $0.30) \times 10^{-7} \mathrm{~mol} \mathrm{~J}^{-1}$, thus approximately equal to $G\left(\mathrm{HO}^{\bullet}\right) / 2$. This suggests a dismutation process i.e., a part of MTF was regenerated during radical reactions. Contrary to what was observed at $\mathrm{pH} 7.15$ and 11.6, at this very acidic $\mathrm{pH}$, the radiolytically-generated $\mathrm{O}_{2}{ }^{\bullet-}$ quasi-exclusively exists in its acidic form $\mathrm{HO}_{2} \bullet$. The latter radical could react with the MTF radical formed after the $\mathrm{HO}^{\bullet}$ attack and HAT from MTF, according to the following reaction:

$$
[\mathrm{MTF}-\mathrm{H}]^{\bullet}+\mathrm{HO}_{2}^{\bullet} \rightarrow \mathrm{MTF}+\mathrm{O}_{2}
$$

Reaction (2) most probably competes with the other reactions that lead to the formation of the oxidation products of MTF. Thus, the radiolytic yield of MTF consumption was lower than $G\left(\mathrm{HO}^{\circ}\right)$. At this acidic $\mathrm{pH}, 4,2,1$-AIMT was the main oxidation product formed (51\%), the second being MBG (38\%) whereas MTFOOH only accounted for $11 \%$ and no 2, 4-AMT was formed. The sum of the $G$-values for the oxidation products was $1.64 \times 10^{-7} \mathrm{~mol} \mathrm{~J}^{-1}$ (Table 1 ), which was again very close to $G(-\mathrm{MTF})$ at this $\mathrm{pH}$.

\section{Conformational features of MTF}

To the best of our knowledge, no quantum-chemical studies have been performed for metformin and a detailed analysis of the conformational feature is instructive for the sake of the present work. Several studies reported on crystallographic structure of MTF derivatives, namely metformin hydrochloride, ${ }^{19}$ $N, N$-dimethylbiguanidium nitrate ${ }^{20}$ and metal complexes with MTF or similar derivatives. ${ }^{21-24}$ For the complexes, the metals form bonds with the nitrogen atoms N6 and N7 of MTF (Fig. 1), constraining a specific conformation. These studies highlighted the importance of $\pi$-conjugation and inter-molecular $\mathrm{H}$-bonding. Quantum chemistry allows an accurate description of the conformational characteristics of MTF (for the non-, mono- and di-protonated forms) and the influence of $\pi$-conjugation. Being related to planarity, the latter property is known to be highly correlated to the antioxidant capacity; the higher the $\pi$-conjugation, the better the $[\mathrm{MTF}-\mathrm{H}]^{\bullet}$ stability and the easier the HAT from MTF for an efficient free radical scavenging.
The conformational analysis was performed taking the protonation state of MTF (i.e., non-, mono- and di-protonated) into account. For non-protonated MTF, six conformers were obtained, the most stable involving one hydrogen bond between N6 and H(N5) of the primary amine group (Fig. 3). This conformer exhibits a strong planar character associated with a strong $\mathrm{sp}^{2}$ character of N5. Two other conformers of interest involve the $\mathrm{H}$ bond between the two imine groups (N6/H(N7) or N7/H(N6)). They are less stable by $3.5 \mathrm{kcal} \mathrm{mol}^{-1}$ due to a weaker $\mathrm{H}$ bonding interaction, as exemplified by a $\mathrm{H}$-bond distance higher by $0.2 \AA$, with respect to the most stable conformer.

As a consequence, the planarity is lost for such conformers and N5 exhibits a stronger $\mathrm{sp}^{3}$ character. The other three conformers exhibit strong steric interaction avoiding planarity.

The most stable conformer of the mono-protonated MTF is the most planar, with a hydrogen bond between $\mathrm{H}(\mathrm{N} 6)$ and N7, and a strong $\mathrm{sp}^{2}$ character for $\mathrm{N} 5$. The other conformers are much less stable by at least $7 \mathrm{kcal} \mathrm{mol}^{-1}$, because of steric hindrance between $\mathrm{H}$ atoms (imine groups) and of subsequent loss of planarity.

The same steric hindrance between $\mathrm{H}$ atoms of imine groups becomes critical and must be avoided for the di-protonated MTF, as similarly observed in the crystal structure of $\mathrm{N}, \mathrm{N}$-dimethylbiguanidium nitrate. $^{20}$ Two symmetrically stable conformers have been isolated, with the torsion angle (N6-C2-N3-C4) equal to $-36^{\circ}$ or $+36^{\circ}$. Even if this structure cannot be planar, nitrogen atoms were found to be almost purely $\mathrm{sp}^{2}$, except for $\mathrm{N} 6$ that exhibited a low $\mathrm{sp}^{3}$ character.

For each protonation state of MTF, one of the nitrogen atoms thus exhibits a mixed $\mathrm{sp}^{2}-\mathrm{sp}^{3}$ character. Consequently, a second conformer has to be taken into account, because of an inversion that could occur for the atom involved. The energy of each of these conformers (i.e., with or without inversion) was
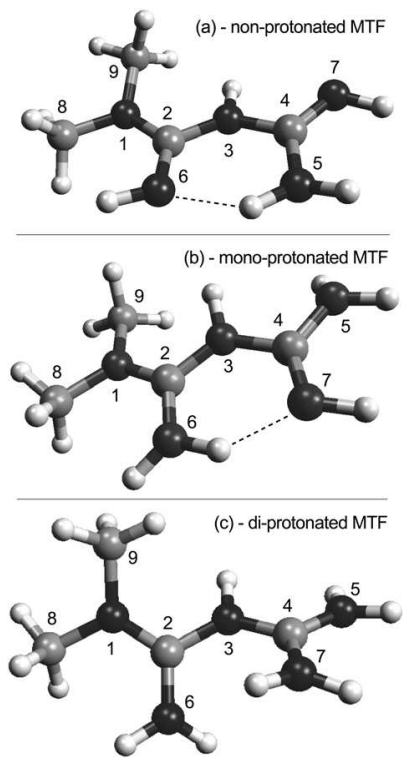

Fig. 3 Three dimensional structures of the most stable conformers obtained for the (a) non-, (b) mono- and (c) di-protonated MTF. 
calculated, and was found to be the same. In addition, both conformers exhibited the same electronic properties.

\section{$\mathrm{H}$-atom abstraction or electron transfer to generate the MTF primary radicals}

The primary attack of $\mathrm{HO}^{\bullet}$ radicals towards MTF occurs according to three possible pathways, namely the pure HAT which is often related to a proton-coupled-electron transfer (PCET), electron transfer (ET) and $\mathrm{HO}^{\bullet}$ addition, corresponding to reactions (3)-(5), respectively:

$$
\begin{gathered}
\mathrm{MTF}+\mathrm{HO}^{\bullet} \rightarrow[\mathrm{MTF}-\mathrm{H}]^{\bullet}+\mathrm{H}_{2} \mathrm{O} \\
\mathrm{MTF}+\mathrm{HO}^{\bullet} \rightarrow \mathrm{MTF}^{+}+\mathrm{HO}^{-} \\
\mathrm{MTF}+\mathrm{HO}^{\bullet} \rightarrow[\mathrm{HO} \cdots \mathrm{MTF}]^{\bullet}
\end{gathered}
$$

Reaction (4) could evolve through heterolytic dissociation (proton transfer, PT) that finally leads to $\mathrm{MTF}^{\bullet}+\mathrm{H}_{2} \mathrm{O}$ and the whole process is often quoted ET-PT. On the basis of previous results obtained at neutral $\mathrm{pH},{ }^{10}$ reaction (5) is not favoured since hydroxymetformin is not detected. The HAT mechanism (reaction (3)) is governed by the bond dissociation enthalpy (BDE) of the $\mathrm{N}-\mathrm{H}$ or $\mathrm{C}-\mathrm{H}$ bonds. If the entropic effect is negligible, which is usually the case for one-atom transfer reaction, $\Delta G_{\mathrm{HAT}}^{\mathrm{o}}$ (i.e., $\left.\Delta G_{\mathrm{HAT}}^{\mathrm{o}}=\left[G^{\mathrm{o}}\left([\mathrm{MTF}-\mathrm{H}]^{\bullet}\right)+G^{\mathrm{o}}(\mathrm{HOH})\right]-\left[G^{\mathrm{o}}(\mathrm{MTF})+G^{\mathrm{O}}\left(\mathrm{HO}^{\bullet}\right)\right]\right)$ is negative if $\mathrm{BDE}(\mathrm{MTF})$ is lower than $\mathrm{BDE}(\mathrm{HO}-\mathrm{H})$. Whatever the protonation state of MTF, the lowest BDE is obtained for the methyl at C8 (Table 2), the one in anti as compared to N6. However, BDE at $\mathrm{C} 9$ being close to that at C8, both methyl groups are equivalent targets for $\mathrm{HO}^{\bullet}$ attack. HAT from the imine and amine groups is less effective, with BDEs higher by about 7 to $14 \mathrm{kcal} \mathrm{mol}^{-1}$ in solution. This result is in good agreement with the chemical structure of the identified oxidation end-products of MTF, in particular MBG and MTFOOH (Fig. 1), which suggests the $N$-dimethyl moiety of MTF as the reactive site. The abovecalculated BDEs are relatively high if compared to O-H BDEs of phenol groups of well-known natural antioxidants (e.g., quercetin, dehydrosylibin), usually ranging from 75 to $85 \mathrm{kcal} \mathrm{mol}^{-1}$. $^{17,25}$ This is consistent with the low second order rate constant of the hydroxyl radical with MTF $\left(k \approx 10^{7} \mathrm{~L} \mathrm{~mol}^{-1} \mathrm{~s}^{-1}\right)$, as determined by Khouri et al. ${ }^{11}$ After HAT from the methyl group, the $[\mathrm{MTF}-\mathrm{H}]^{\bullet}$ primary radical is formed, with a spin density distribution strongly localized on the carbon atom from where the $\mathrm{H}$ atom has been removed (data not shown).

Table 2 Bond dissociation energy (BDE, $\mathrm{kcal} \mathrm{mol}^{-1}$ ) of $\mathrm{C}-\mathrm{H}$ and $\mathrm{N}-\mathrm{H}$ bonds as a function of the protonation state of MTF (non-, mono- and di-protonated). The

\begin{tabular}{|c|c|c|c|c|c|c|}
\hline \multirow[b]{2}{*}{ H-pos } & \multicolumn{2}{|c|}{ Non-protonated } & \multicolumn{2}{|c|}{ Mono-protonated } & \multicolumn{2}{|c|}{ Di-protonated } \\
\hline & $\mathrm{BDE}_{\text {gas }}$ & $\mathrm{BDE}_{\text {solv. }}$ & $\mathrm{BDE}_{\text {gas }}$ & $\mathrm{BDE}_{\text {solv. }}$ & $\mathrm{BDE}_{\text {gas }}$ & $\mathrm{BDE}_{\text {solv. }}$ \\
\hline 3 & 94.9 & 99.5 & 96.2 & 100.7 & 108.3 & 109.5 \\
\hline 5 & 104.5 & 104.3 & 101.8 & 103.4 & 128.8 & 116.1 \\
\hline 6 & 95.5 & 97.8 & 110.9 & - & 120.0 & 111.8 \\
\hline 7 & 99.1 & 101.4 & 104.5 & 104.1 & 132.1 & 118.6 \\
\hline 8 & 88.9 & 90.4 & 93.4 & 91.8 & 102.5 & 92.6 \\
\hline 9 & 89.6 & 91.3 & 94.2 & 93.0 & 103.4 & 93.2 \\
\hline
\end{tabular}
solvent (water, $\varepsilon=78.39$ ) was not $\left(\mathrm{BDE}_{\text {gas }}\right)$ or was $\left(\mathrm{BDE}_{\text {solvent }}\right)$ taken into account for calculation (using a PCM approach). H-positions refer to Fig. 1
Table $3 \Delta H_{\mathrm{ET}}$ and $\Delta G_{\mathrm{ET}}\left(\mathrm{kcal} \mathrm{mol}^{-1}\right)$ for the electron transfer (ET) mechanism as a function of the protonation state of MTF (non-, mono- and di-protonated)

\begin{tabular}{llllll}
\hline & $\Delta H_{\mathrm{ET}}$ & & & $\Delta G_{\mathrm{ET}}$ & \\
\cline { 2 - 3 } MTF & Gas & Solvent & & Gas & Solvent \\
\hline Non-protonated & 136.3 & 16.1 & & 136.8 & 16.1 \\
Mono-protonated & 252.8 & 31.5 & & 252.3 & 32.8 \\
Di-protonated & 371.2 & 64.7 & & 361.6 & 66.2
\end{tabular}

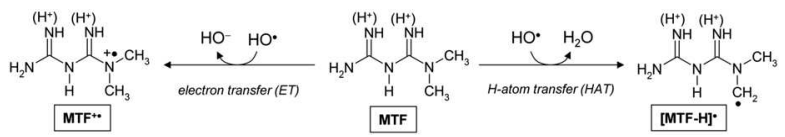

Scheme 1 Proposed reaction mechanism of MTF primary radical formation, via $\mathrm{H}$-atom and electron transfer.

The electron transfer mechanism (ET, reaction (4)) is kinetically governed by the ionization potential and the Gibbs energy of the reaction i.e., $\Delta G_{\mathrm{ET}}^{\mathrm{o}}=\left[G^{\mathrm{O}}\left(\mathrm{MTF}^{+\bullet}\right)+G^{\mathrm{O}}\left(\mathrm{HO}^{-}\right)\right]-\left[G^{\mathrm{O}}(\mathrm{MTF})+G^{\mathrm{O}}\left(\mathrm{HO}^{\bullet}\right)\right]$. For this mechanism, $\Delta H_{\mathrm{ET}}^{\mathrm{o}}$ and $\Delta G_{\mathrm{ET}}^{\mathrm{o}}$ have been calculated and are reported in Table 3. As expected, $\Delta G_{\mathrm{ET}}^{\mathrm{o}}$ increases as MTF becomes more protonated i.e., ET is somehow activated in the deprotonated forms. If solvent is not included in calculation, this mechanism is thermodynamically not possible as $\Delta G_{\mathrm{ET}}^{\mathrm{o}}$ values are too high, even at basic $\mathrm{pH}\left(+136.8 \mathrm{kcal} \mathrm{mol}^{-1}\right)$. When including the solvent, $\Delta G_{\mathrm{ET}}^{\mathrm{o}}$ dramatically decreases whatever the protonation state of MTF, to reach $16.1,32.8$ and $66.2 \mathrm{kcal} \mathrm{mol}^{-1}$ for the non-, mono- and di-protonated MTF, respectively. Such an influence of the solvent was previously observed for flavonoid compounds ${ }^{26}$ and was attributed to the strong stabilizing effect of the solvent towards the radical cation formed after ET. As a consequence, the ET mechanism cannot be viewed as minor, mainly for the non-protonated MTF.

The reaction mechanisms for MTF primary radical generation are summarized in Scheme 1. Whatever the protonation state of MTF, the HAT mechanism leads to a carbon-centered radical located at C8 (or C9), on the $N$-dimethyl moiety of MTF ([MTF $-\mathrm{H}]^{\bullet}$ ). Depending on $\mathrm{pH}$ conditions, the ET mechanism is in competition and can simultaneously lead to another primary radical of MTF $\left(\mathrm{MTF}^{+}\right)$. Because of relatively high Gibbs energy of formation of $\mathrm{MTF}^{+}$(Table 3), the latter mechanism is likely to occur only for the non- and mono-protonated MTF.

\section{$[\mathrm{MTF}-\mathbf{H}]^{\bullet}$ evolution}

Based on the above joint experimental and theoretical results, a comprehensive reaction mechanism of the MTF one-electron oxidation is proposed. At $\mathrm{pH} 7.15$ and 11.6, the $G(-\mathrm{MTF})$ radiolytic yield of MTF disappearance is close to that of $\mathrm{HO}^{\bullet}$ production $\left(G\left(\mathrm{HO}^{\bullet}\right)\right)$. Thus, the reaction between one molecule of MTF and one $\mathrm{HO}^{\bullet}$ radical leads to several oxidation end-products without any regeneration of MTF (dismutation process).

Starting from the $[\mathrm{MTF}-\mathrm{H}]^{\bullet}$ primary radical, two main reaction mechanisms are considered i.e., dioxygen addition or cyclisation. The former reaction is initiated by the addition of either dioxygen or superoxide radical onto $[\mathrm{MTF}-\mathrm{H}]^{\bullet}$, yielding a peroxyl radical or a peroxyl anion, respectively. The first addition-mechanism (addition of triplet dioxygen on $[\mathrm{MTF}-\mathrm{H}]^{\bullet}$ ) 
Table 4 Formation of $\mathrm{MTFOO}^{-}$or $\mathrm{MTFOO}^{-}$after addition of triplet dioxygen ${ }^{3} \mathrm{O}_{2}$ or the superoxide anion $\mathrm{O}_{2}{ }^{\bullet-}$ onto the MTF primary radical [MTF $\left.-\mathrm{H}\right]^{\bullet}$, as a function of the protonation state of MTF. $\Delta G^{\circ}$ and $\Delta G^{\#}$ values correspond to the difference of Gibbs free energy $\left(\mathrm{kcal} \mathrm{mol}^{-1}\right)$ between the final and the initial compound, and the corresponding Gibbs energy of activation $\left(\mathrm{kcal} \mathrm{mol}^{-1}\right)$, respectively

\begin{tabular}{llllll}
\hline \multirow{2}{*}{ MTF } & \multicolumn{2}{c}{ MTFOO $^{\bullet}$} & & & MTFOO $^{-}$ \\
\cline { 2 - 3 } \cline { 5 - 6 } & $\Delta G^{\mathrm{o}}$ & $\Delta G^{\#}$ & & $\Delta G^{\mathrm{o}}$ & $\Delta G^{\#}$ \\
\hline Non-protonated & -19.2 & 57.0 & & -29.6 & 42.1 \\
Mono-protonated & -16.3 & 89.6 & -45.7 & 15.3 \\
Di-protonated & -12.6 & - & - & - \\
\hline
\end{tabular}

is obviously favoured at a position where the spin density is the most important, namely C8 and C9. This addition is very exothermic with $\Delta G^{\circ}=-19.2,-16.3$ and $-12.6 \mathrm{kcal} \mathrm{mol}^{-1}$ for the non-, mono- and di-protonated MTF, respectively (Table 4). However, this is a limiting step as the corresponding calculated energy barrier is very high. Such a high-energy barrier is attributed to the strong reorganization of the carbon atom from the $\mathrm{sp}^{2}$ to $\mathrm{sp}^{3}$ hybridization state. This barrier increases while $\mathrm{pH}$ decreases, which is rationalized by the spin density distribution in the corresponding transition state $\left(\mathrm{MTFOO}^{\#}\right)$ at $\mathrm{C} 8$ and the $\mathrm{O}$ atom of dioxygen. For the nonprotonated MTF, the calculated spin density is 0.15 and 0.67 for both atoms, respectively, while for the mono-protonated MTF, it is 0.07 and 0.52 , respectively. As a consequence, the electron pair that leads to bond formation in $\mathrm{MTFOO}^{\#}$ is stronger for the nonprotonated than for the mono-protonated form of MTF. The corresponding $[\mathrm{C}-\mathrm{O}]$ distance is indeed lower in $\mathrm{MTFOO}^{\#}$ of the former state ( 0.172 vs. $0.202 \mathrm{~nm}$ for both forms, respectively) and the corresponding energy barrier is higher. The second additionmechanism (i.e., addition of the superoxide anion to the MTF primary radical $[\mathrm{MTF}-\mathrm{H}]^{\bullet}$ ) appears favourable for two reasons: the process is more exothermic than the dioxygen addition because of lower Gibbs energy $\left(-29.6\right.$ and $-45.7 \mathrm{kcal} \mathrm{mol}^{-1}$ for non- and mono-protonated MTF, respectively), and the corresponding energy barrier is lower. This addition process yields a peroxyl anion, evolving into hydroperoxometformin (MTFOOH), as summarized in Scheme 2.

The second reaction mechanism that is considered with [MTF $-\mathrm{H}]^{\bullet}$ generates the cyclic 4,2,1-AIMT (and 2,4-AMT, chemically generated from 4,2,1-AIMT as previously suggested). ${ }^{10}$ The cyclisation process must occur by the formation of a bond between N7 and C8 (or C9). Nonetheless, regarding the conformation of MTF and $[\mathrm{MTF}-\mathrm{H}]^{\circ}$, this mechanism is not trivial because the two atoms are not spatially close to each other (Fig. 3). Thus 4,2, 1-AIMT formation was investigated as a two-step mechanism, i.e. (1) torsion of the $\mathrm{C} 4-\mathrm{N} 3-\mathrm{C} 2-\mathrm{N} 1$ dihedral that leads to a reorganized MTF and (2) N-C bond formation. The energetic schemes are presented in Fig. 4 for the different forms of MTF, namely non-, mono- and di-protonated. Solvent effects decreased all energetic barriers and intermediate stabilities, but provided the same trend as with the gas phase calculations (Fig. 4). The second (bond formation) step of 4,2,1-AIMT formation is the limiting step, the first (re-arrangement) step appearing as a faster process (Gibbs energy of activation ranging from 2.1 to $3.4 \mathrm{kcal} \mathrm{mol}^{-1}$ from the di- to the non-protonated form). The Gibbs energies of activation

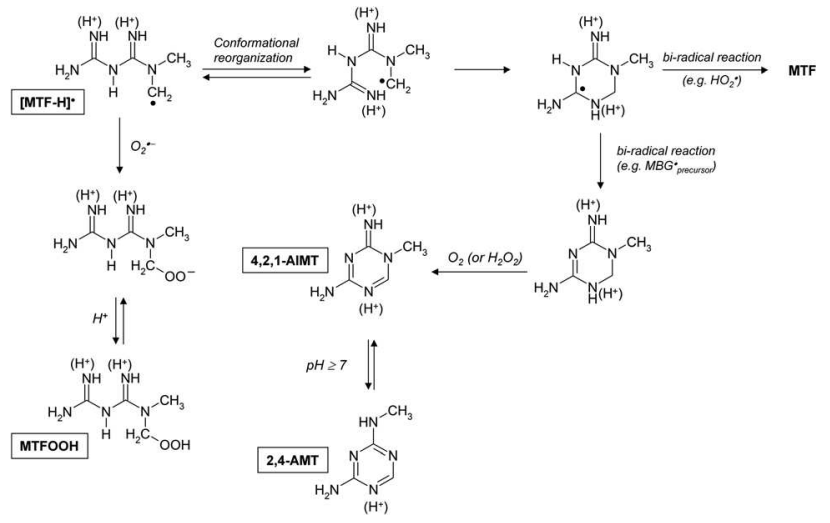

Scheme 2 Proposed reaction mechanism of MTFOOH, 4,2,1-AIMT and 2,4-AMT formation, from the MTF primary radical [MTF $-\mathrm{H}]^{\bullet}$.

of the second step were $18.6 \mathrm{kcal} \mathrm{mol}^{-1}, 9.7 \mathrm{kcal} \mathrm{mol}^{-1}$ and $20.2 \mathrm{kcal} \mathrm{mol}^{-1}$ (PCM solvent calculations), for the non-, monoand di-protonated MTF, respectively. The 4,2,1-AIMT formation appears more favourable under neutral and acidic $\mathrm{pH}$ conditions as (i) the $[\mathrm{MTF}-\mathrm{H}]^{\bullet}$ rearrangement is easier for the di-protonated MTF and less favourable for the other two protonation states of MTF, and (ii) the $\mathrm{N}-\mathrm{C}$ bond formation is favoured at quasi-neutral $\mathrm{pH}$, as suggested by the low energy barrier. At $\mathrm{pH}$ 7.15, MTF is exclusively in its mono-protonated form and the two cyclic products, 4,2,1-AIMT and 2,4-AMT, account for $45 \%$ of the oxidation end-products formed (Table 1). If the mono-protonated MTF is assumed to be the most favourable protonation state for 4,2 , 1-AIMT formation (low energy of rearrangement and low transition state energy), the cyclisation at $\mathrm{pH} 2.8$ and $\mathrm{pH} 11.6$ could be assumed to proceed via acid-base equilibrium between di- and mono-protonated MTF on one hand, and mono- and nonprotonated MTF on the other hand. Thus, 4,2,1-AIMT and 2,4-AMT are also formed at both $\mathrm{pH} 2.8$ and 11.6, but to a slightly less extent at the latter $\mathrm{pH}$ because in this case the rearrangement step appears to be slightly slower than at lower $\mathrm{pH}$.

Scheme 2 proposes a reaction mechanism for the formation of 4,2,1-AIMT and 2,4-AMT. After conformational reorganization of $[\mathrm{MTF}-\mathrm{H}]^{\bullet}$ as discussed above, the N7-C8(C9) bond is formed and the cyclic [MTF $-\mathrm{H}^{\bullet}$ radical is generated. A bi-radical reaction involving other radical species present in solution, such as $\mathrm{MBG}_{\text {precursor }}^{\circ}$ (the reaction mechanism of MBG formation is discussed below), converts the cyclic [MTF $-\mathrm{H}]^{\bullet}$ into a neutral molecule, which is further oxidized by oxygen (or hydrogen peroxide, produced during water radiolysis) leading to 4,2 , 1-AIMT. Depending on $\mathrm{pH}$, this compound could undergo a methyl transfer from N1 to N6 to isomerize into 2,4-AMT. For the methyl transfer reaction to occur a sufficient spin density on N6 is required, as a classic proton transfer. As N6 is protonated at $\mathrm{pH} 2.8$, the 2,4-AMT isomer is not observed (Table 1).

\section{$\mathrm{MTF}^{+\bullet}$ evolution}

Starting from the ET-induced $\mathrm{MTF}^{+} \bullet$ radical cation, Scheme 3 proposes a comprehensive reaction mechanism for MBG formation. In this mechanism, the methyl group at C8 (or C9) of $\mathrm{MTF}^{+}$is 
(a) - non-protonated MTF

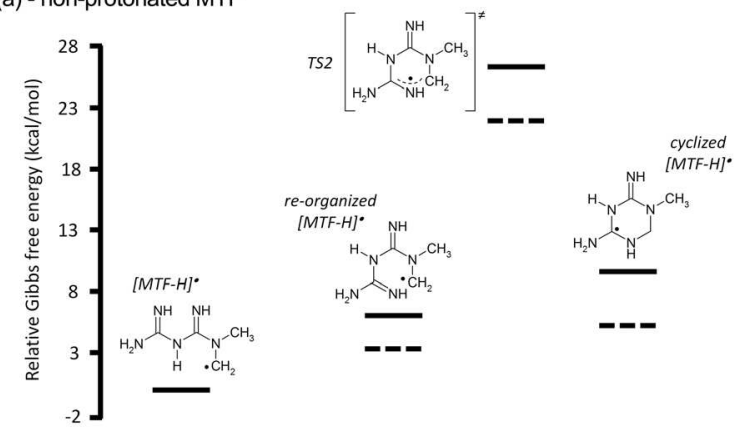

(b) - mono-protonated MTF

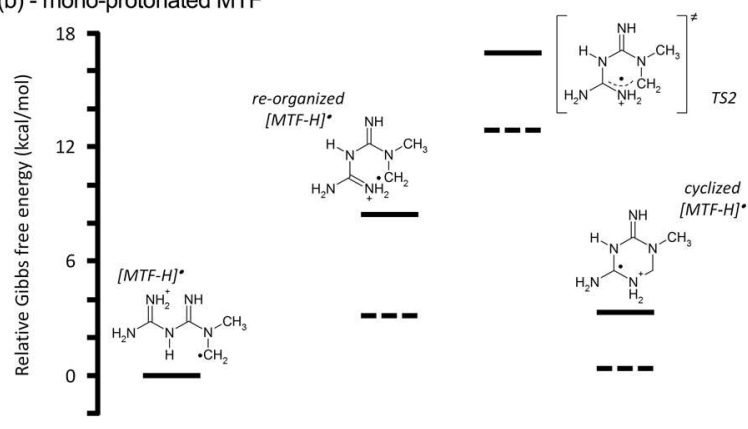

(c) - di-protonated MTF

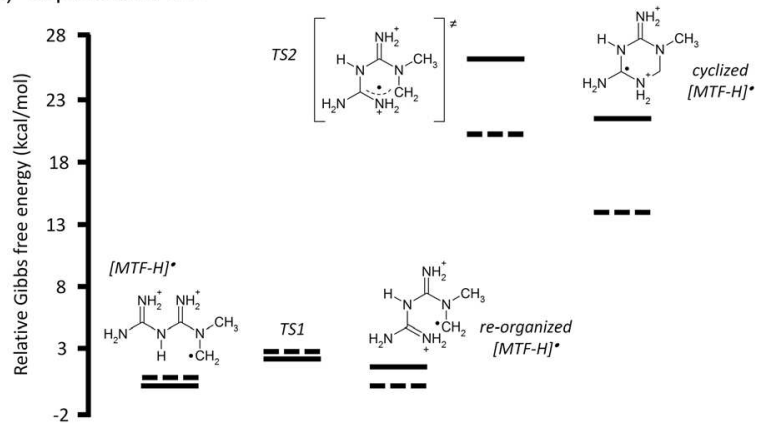

Fig. 4 Energetic schemes for the cyclization process for the (a) non-, (b) monoand (c) di-protonated MTF, in the gas phase (solid line) and in the presence of solvent (dashed line).

attacked by $\mathrm{HO}^{-}$(generated from $\mathrm{HO}^{\bullet}$ during the ET mechanism), yielding $\mathrm{MBG}_{\text {precursor }}^{\bullet}$ and $\mathrm{CH}_{3} \mathrm{OH}$. A bi-radical reaction, involving other radical species present in solution including the cyclic $[\mathrm{MTF}-\mathrm{H}]^{\bullet}$, converts $\mathrm{MBG}_{\text {precursor }}^{\bullet}$ into MBG.

As described above, the ET process is highly unfavourable at low $\mathrm{pH}$, but the Gibbs energy of formation dramatically decreases when $\mathrm{pH}$ increases (Table 3). Thus, the formation of MBG appears to be favoured at basic $\mathrm{pH}$, which fully agrees with the experimental results (Table 1), in such a way that MBG is the major oxidation product at $\mathrm{pH}$ 11.6. In this case, the ET mechanism is considered as the major mechanism of MTF oxidation.

One of the crucial steps in MBG formation is also the $\mathrm{CH}_{3}{ }^{+}$ abstraction. The most trivial assumption is that $\mathrm{CH}_{3}{ }^{+}$is scavenged by $\mathrm{HO}^{-}$, according to the following reaction:

$$
\mathrm{MTF}^{+} \bullet+\mathrm{HO}^{-} \rightarrow \mathrm{MBG}_{\text {precursor }}^{\bullet}+\mathrm{CH}_{3} \mathrm{OH}
$$

Calculations at the DFT level have shown that reaction (6) is exothermic, with a Gibbs energy of $-39.3,-30.8$ and

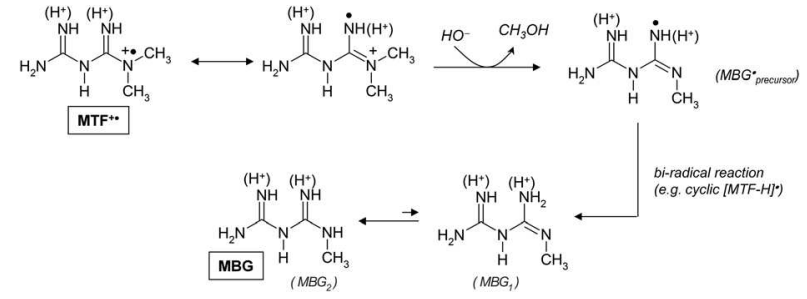

Scheme 3 Proposed reaction mechanism of MBG formation, from the MTF primary radical $\mathrm{MTF}^{+\bullet}$.

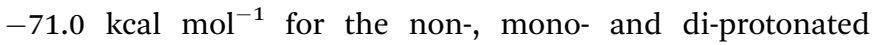
MTF, respectively. This mechanism is probably concerted, and involves $\mathrm{HO}^{-}$generated from $\mathrm{HO}^{\bullet}$ during ET. The following steps are well-known bi-radical reactions that occur in radiolytic solutions. MBG may exist as two tautomers $\left(\mathrm{MBG}_{1}\right.$ and $\mathrm{MBG}_{2}$, Scheme 3), $\mathrm{MBG}_{2}$ being preferred by around $5 \mathrm{kcal} \mathrm{mol}^{-1}$ (according to the Boltzmann distribution, $5 \mathrm{kcal} \mathrm{mol}^{-1}$ corresponds to a $0.02 / 99.98 \%$ ratio).

\section{Conclusions}

A comprehensive reaction mechanism of MTF one-electron oxidation by $\mathrm{HO}^{\bullet} / \mathrm{O}_{2}{ }^{-}$radical species has been established as a function of the $\mathrm{pH}$. The HPLC/MS quantification of both MTF consumption and formation of oxidation products was achieved, after radio-induced oxidation at increasing radiation doses. The four oxidation products, i.e., MTFOOH, MBG, 4,2, 1-AIMT and 2,4-AMT, and their corresponding radiolytic yields allowed proposing two distinct mechanisms for the reaction of $\mathrm{HO}^{\bullet}$ with MTF. At pH 11.6 and 7.15, the sum of all oxidation product yields $\left(\sum P_{\mathrm{ox}}\right)$ was similar to $G\left(\mathrm{HO}^{\bullet}\right)$, which was related to the absence of the dismutation process. In this case, the oxidation results in the formation of MBG as the major product, MTFOOH, 2,4-AMT and 4,2,1-AIMT being minor products. By contrast, at $\mathrm{pH} 2.8, \sum P_{\mathrm{ox}}$ was close to $\frac{1}{2} G\left(\mathrm{HO}^{\bullet}\right)$, which suggested a dismutation mechanism allowing reformation of MTF. At this low $\mathrm{pH}, 4,2,1$-AIMT is the major oxidation product, together with MTFOOH and MBG. Quantum calculations fully rationalized the different steps, according to $\mathrm{pH}$ i.e., the protonation state. This provides an accurate tool to investigate oxidative reactions of biologically active compounds under various conditions.

\section{Acknowledgements}

The authors are indebted to Dr Averbeck for gamma irradiation facilities at the Institute Curie - Paris. The authors thank the "Conseil Régional du Limousin" for financial support and CALI (CAlcul en LImousin) for computing facilities. Research in Limoges is also supported by the COST action CM0804 "Chemical Biology with Natural Compounds". The authors gratefully acknowledge the support from the Operational Program Research and Development for Innovations - European Regional Development Fund (project CZ.1.05/2.1.00/03.0058 of the Ministry of Education, Youth and Sports of the Czech Republic). 


\section{References}

1 G. Zhou, R. Myers, Y. Li, Y. Chen, X. Shen, J. Fenyk-Melody, M. Wu, J. Ventre, T. Doebber, N. Fujii, N. Musi, M. F. Hirshman, L. J. Goodyear and D. E. Moller, J. Clin. Invest., 2001, 108, 1167-1174.

2 R. M. Memmott, J. R. Mercado, C. R. Maier, S. Kawabata, S. D. Fox and P. A. Dennis, Cancer Prev. Res., 2010, 3, 1066-1076.

3 Y. Tanaka, H. Uchino, T. Shimizu, H. Yoshii, M. Niwa, C. Ohmura, N. Mitsuhashi, T. Onuma and R. Kawamori, Eur. J. Pharmacol., 1999, 376, 17-22.

4 D. Ruggiero-Lopez, M. Lecomte, G. Moinet, G. Patereau, M. Lagarde and N. Wiernsperger, Biochem. Pharmacol., 1999, 58, 1765-1773.

5 D. Bonnefont-Rousselot, B. Raji, S. Walrand, M. GardesAlbert, D. Jore, A. Legrand, J. Peynet and M. P. Vasson, Metabolism, 2003, 52, 586-589.

6 A. Chakraborty, S. Chowdhury and M. Bhattacharyya, Diabetes Res. Clin. Pract., 2011, 93, 56-62.

7 O. O. Erejuwa, S. A. Sulaiman, M. S. Wahab, S. K. Salam, M. S. Salleh and S. Gurtu, Int. J. Mol. Sci., 2010, 11, 2056-2066.

8 X. Hou, J. Song, X. N. Li, L. Zhang, X. Wang, L. Chen and Y. H. Shen, Biochem. Biophys. Res. Commun., 2010, 396, 199-205.

9 A. Esteghamati, D. Eskandari, H. Mirmiranpour, S. Noshad, M. Mousavizadeh, M. Hedayati and M. Nakhjavani, Clin. Nutr., 2012, 32, 179-185.

10 F. Collin, H. Khoury, D. Bonnefont-Rousselot, P. Thérond, A. Legrand, D. Jore and M. Gardès-Albert, J. Mass Spectrom., 2004, 39, 890-902.

11 H. Khouri, F. Collin, D. Bonnefont-Rousselot, A. Legrand, D. Jore and M. Gardes-Albert, Eur. J. Biochem., 2004, 271, 4745-4752.

12 P. J. Pentikainen, Int. J. Clin. Pharmacol., Ther. Toxicol., 1986, 24, 213-220.

13 H. Fricke and S. Morse, Am. J. Roentgenol. Radium Ther., 1927, 18, 430-432.

14 J. W. T. Spinks and R. J. Woods, Introduction to Radiation Chemistry, John Wiley \& sons, New York, 1990, pp. 243-313.

15 B. H. J. Bielski, D. E. Cabelli, R. L. Arudi and A. B. Ross, J. Phys. Chem. Ref. Data, 1985, 14, 1041-1100.

16 M. Leopoldini, T. Marino, N. Russo and M. Toscano, Theor. Chem. Acc., 2004, 111, 210-216.
17 P. Trouillas, P. Marsal, D. Siri, R. Lazzaroni and J. L. Duroux, Food Chem., 2006, 97, 679-688.

18 M. J. T. Frisch, G. W. Trucks, H. B. Schlegel, G. E. Scuseria, M. A. Robb, J. R. Cheeseman, J. A. Montgomery, Jr., T. Vreven, K. N. Kudin, J. C. Burant, J. M. Millam, S. S. Iyengar, J. Tomasi, V. Barone, B. Mennucci, M. Cossi, G. Scalmani, N. Rega, G. A. Petersson, H. Nakatsuji, M. Hada, M. Ehara, K. Toyota, R. Fukuda, J. Hasegawa, M. Ishida, T. Nakajima, Y. Honda, O. Kitao, H. Nakai, M. Klene, X. Li, J. E. Knox, H. P. Hratchian, J. B. Cross, V. Bakken, C. Adamo, J. Jaramillo, R. Gomperts, R. E. Stratmann, O. Yazyev, A. J. Austin, R. Cammi, C. Pomelli, J. W. Ochterski, P. Y. Ayala, K. Morokuma, G. A. Voth, P. Salvador, J. J. Dannenberg, V. G. Zakrzewski, S. Dapprich, A. D. Daniels, M. C. Strain, O. Farkas, D. K. Malick, A. D. Rabuck, K. Raghavachari, J. B. Foresman, J. V. Ortiz, Q. Cui, A. G. Baboul, S. Clifford, J. Cioslowski, B. B. Stefanov, G. Liu, A. Liashenko, P. Piskorz, I. Komaromi, R. L. Martin, D. J. Fox, T. Keith, M. A. Al-Laham, C. Y. Peng, A. Nanayakkara, M. Challacombe, P. M. W. Gill, B. Johnson, W. Chen, M. W. Wong, C. Gonzalez and J. A. Pople, Gaussian 03, Revision C.02, Gaussian Inc., Wallingford, 2004.

19 M. Hariharan, S. S. Rajan and R. Srinivasan, Acta Crystallogr., Sect. C: Cryst. Struct. Commun., 1989, 45, 911-913.

20 M. Zhu, L. Lu and P. Yang, Acta Crystallogr., Sect. E: Struct. Rep. Online, 2003, 59, o586-0588.

21 F. Bentefrit, G. Morgant, B. Viossat, S. Leonce, N. Guilbaud, A. Pierre, G. Atassi and H. D. Nguyen, J. Inorg. Biochem., 1997, 68, 53-59.

22 R. Olar, M. Badea, D. Marinescu, M. C. Chifiriuc, C. Bleotu, M. N. Grecu, E. E. Iorgulescu and V. Lazar, Eur. J. Med. Chem., 2010, 45, 3027-3034.

23 P. Lemoine, M. Chiadmi, V. Bissery, A. Tomas and B. Viossat, Acta Crystallogr., Sect. C: Cryst. Struct. Commun., 1996, 52, 1430-1436.

24 B. Viossat, A. Tomas and N.-H. Dung, Acta Crystallogr., Sect. C: Cryst. Struct. Commun., 1995, 51, 213-215.

25 P. Trouillas, P. Marsal, A. Svobodova, J. Vostalova, R. Gazak, J. Hrbac, P. Sedmera, V. Kren, R. Lazzaroni, J. L. Duroux and D. Walterova, J. Phys. Chem. A, 2008, 112, 1054-1063.

26 D. Kozlowski, P. Trouillas, C. Calliste, P. Marsal, R. Lazzaroni and J. L. Duroux, J. Phys. Chem. A, 2007, 111, 1138-1145. 